\title{
Expedient Synthesis of Bis(imidazolium) Dichloride Salts and Bis(NHC) Complexes from Imidazoles using DMSO as a Key Polar Additive
}

\author{
Kyle R. Penn, Evan J. Anders, and Vincent N. G. Lindsay* \\ Department of Chemistry, North Carolina State University, 2620 Yarbrough Drive, Raleigh, North Carolina 27695, USA. \\ Supporting Information Placeholder
}

\begin{abstract}
A general approach for the synthesis of bis(imidazolium) dichloride salts from imidazoles and dichloroalkanes is reported. Typical limitations of this reaction for the formation of methylene-bridged derivatives are addressed herein through the use of an excess $\mathrm{CH}_{2} \mathrm{Cl}_{2}$ in the presence of DMSO as a polar cosolvent, significantly improving conversion rates presumably via stabilization of the initial $\mathrm{S}_{\mathrm{N}} 2$ transition state. The method was also shown to be applicable to the formation of bis(pyridinium) dichloride salts from pyridine derivatives, and to the direct synthesis of metal-bis(NHC) complexes from imidazoles.
\end{abstract}

Metal-bis(carbene) complexes, typically synthesized from the corresponding bis(azolium) dihalide salts, constitute robust and highly effective catalysts in a wide range of chemical transformations ${ }^{1,2,3}$ including cross-coupling reactions, ${ }^{3 a-d}$ imine reduction, ${ }^{3 e}$ redox alkylation, ${ }^{3 \mathrm{f}-\mathrm{g}} \mathrm{C}-\mathrm{H} / \mathrm{C}-\mathrm{X}$ activation, ${ }^{\text {3h-l }}$ Nazarov cyclization, ${ }^{3 \mathrm{~m}}$ water oxidation $^{3 \mathrm{n}}$ and carbon dioxide reduction processes. ${ }^{30}$ Moreover, certain iridium(III)-bis(NHC) complexes have been identified as anti-cancer agents, ${ }^{4}$ while gold analogues were previously employed as halide sensors. ${ }^{5}$ The corresponding bis(azolium) salts have also been studied as ionic liquids ${ }^{6}$ and as thermochromic and photoluminescent materials, ${ }^{7}$ often accessed from the dichloride derivatives via anion exchange. While bis(azolium) dichloride salts are widely used in organic and organometallic chemistry, their efficient access from $N$-substituted imidazoles has been seriously impeded by the poor electrophilicity of 1,1-dichloroalkanes such as dichloromethane in nucleophilic substitution processes. Indeed, known routes to access these salts typically lack generality and practicality, requiring either prolonged heating in PEG 200 as solvent (Scheme 1a) ${ }^{3 a}$ or the use of an ultra-high pressure apparatus (Scheme 1b), where yields were found to drastically decrease with longer $N$-alkyl substituents. After taking a closer look at these procedures, we noted that a common feature involve the use of stoichiometric dichloromethane as electrophile rather than a large excess, presumably to avoid isolation of the mono-alkylated $\mathrm{N}$-chloromethyl imidazolium intermediate instead of the desired bis(azolium) salt. ${ }^{3 a, 8,9}$ Due to the poor electrophilicity of dichloromethane, these reactions are often run at temperatures well above its boiling point in sealed vessels to prevent loss of this limiting reagent during the reaction, making the procedures difficult to reproduce on different scales. While the kinetic profiles of these transformations are not well-known, analogous processes involving pyridine derivatives as nucleophiles have previously been thoroughly investigated (eq 1). ${ }^{10,11}$

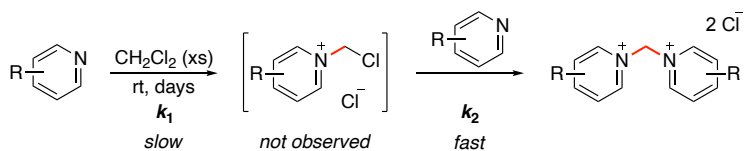

Particularly, Wamser and co-workers determined that the second substitution step is so much faster than the first one that the $N$ chloromethyl pyridinium chloride intermediate cannot be observed or isolated even when a large excess of dichloromethane was employed, and only the final bis(pyridinium) dichloride salt is obtained. ${ }^{1{ }^{0 a}}$ Cognizant of the fact that $N$-alkyl imidazoles and pyridine derivatives possess similar nucleophilicities, ${ }^{12}$ we reasoned that an analogous kinetic profile might be operative, potentially allowing the use of excess dichloromethane in the production of bis(azolium) dichloride salts as well. Herein, we report an expedient and general method for the formation of bis(imidazolium) dichloride salts via the use of an excess $\mathrm{CH}_{2} \mathrm{Cl}_{2}$ in the presence of DMSO as a key polar additive (Scheme 1c). The method could be extended to the production of bis(pyridinium) dichloride salts with excellent efficiency, and the subsequent addition transition metal salts was shown to lead to the production of various metal-bis(NHC) complexes directly from imidazoles. Considering the ubiquity of bis(azolium) salts and bis(NHC) complexes, ${ }^{1-7}$ this practical approach should find utility in future research endeavors involving these species.

\section{Scheme 1. Synthetic Methods to Bis(azolium) Dichloride Salts}

$$
\begin{aligned}
& \text { (a) Strassner's work: Using PEG } 200 \text { as solvent }
\end{aligned}
$$

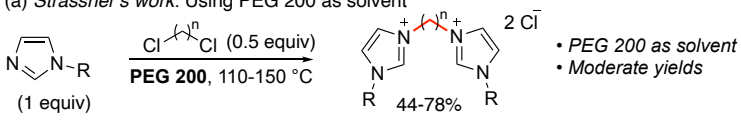

$$
\begin{aligned}
& \text { (b) Harwood's work: Ultra-high pressure synthesis }
\end{aligned}
$$

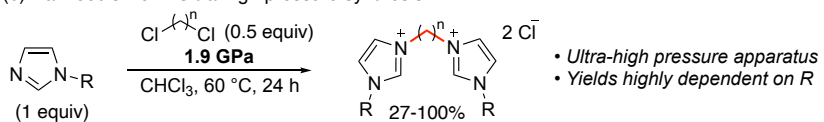

$$
\begin{aligned}
& \text { (c) This work: DMSO as key additive in the presence of excess dichloroalkane } \\
& \text { (c) This work: DMSO as key additive in the presence of excess dichloroalkane } \\
& \mathrm{N}_{\mathbb{N}-\mathrm{R}} \frac{\text { DMSO (0.8 equiv) }}{[4 \mathrm{M}], 100^{\circ} \mathrm{C}, 24 \mathrm{~h}} \\
& \begin{array}{llll}
\text { (1 equiv) } \quad \mathrm{n}=1,2,3 & \mathrm{R} & \mathrm{R} & \text { complexes from imidazoles } \\
\mathrm{R} & =\mathrm{Alk}, \mathrm{Ar} & &
\end{array} \\
& \text { i. } \mathrm{MX}_{\mathrm{n}} \mathrm{Me}_{\mathrm{DMSO}_{2}}
\end{aligned}
$$


Our initial studies focused on the formation of bis(imidazolium) salt 2a from $N$-methylimidazole (1a) in the presence of an excess of dichloromethane (Table 1). A number of cosolvents were first evaluated at $70{ }^{\circ} \mathrm{C}$ for their ability to improve initial conversion rates of the transformation, presumably via stabilization of the polar $\mathrm{S}_{\mathrm{N}} 2$ transition state leading to the $\mathrm{N}$-chloromethyl imidazolium intermediate (entries 1-13). ${ }^{13}$ Remarkably, such a species was never observed in any case, in accordance with our hypothesis stating that the second substitution step is likely significantly faster than the first one, in analogy to the formation of bis(pyridinium) dichloride salts (vide supra). ${ }^{10 a}$ From all cosolvents evaluated, DMSO proved to be superior (entry 13), and increasing both the temperature and concentration led to a significant improvement in yields (entries 14-21). Notably, while the absence of DMSO led to comparable yields at low conversions (see entry 2 vs 13-14), the beneficial effect of such a polar additive became more apparent at higher temperatures (see e.g., entry 19 vs 20 ), to the point where full conversion could not be reached in a reasonable time in the absence of this cosolvent. Under the optimized conditions, bis(imidazolium) salt $2 \mathrm{a}$ could be obtained in $94 \%$ isolated yield and the procedure could be applied on multigram scale with similar efficiency (see entry 21 and Scheme 2, 2a).

Table 1. Optimization of the Cosolvent and Reaction Conditions

\begin{tabular}{|c|c|c|c|c|c|}
\hline$\underset{1 a}{N_{\Downarrow}}$ & $\begin{array}{r}\mathrm{CH}_{2} \\
\text { cc } \\
\text { temp } \\
{[\text { con }}\end{array}$ & $\begin{array}{l}\begin{array}{l}x \text { equiv) } \\
\text { Ivent } \\
\text { ure, } 24 \mathrm{~h} \\
\text { tration] }\end{array} \\
\mathrm{Me}^{\prime}\end{array}$ & $\mathrm{Cl}$ & 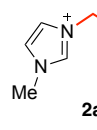 & $\sum_{\mathrm{Me}}$ \\
\hline entry & $\begin{array}{l}\mathrm{CH}_{2} \mathrm{Cl}_{2} \\
\text { equiv }\end{array}$ & cosolvent & $\begin{array}{l}\text { temp. } \\
\left({ }^{\circ} \mathrm{C}\right)\end{array}$ & $\begin{array}{l}\text { conc. } \\
\text { (M) }\end{array}$ & $\begin{array}{l}\text { yield } \\
(\%)^{a}\end{array}$ \\
\hline 1 & 7.8 & - & 70 & 2.0 & 7 \\
\hline 2 & 3.0 & - & 70 & 5.2 & 15 \\
\hline 3 & 3.0 & $\mathrm{Et}_{2} \mathrm{O}$ & 70 & 2.0 & 4 \\
\hline 4 & 3.0 & $\mathrm{DMF}$ & 70 & 2.0 & 7 \\
\hline 5 & 3.0 & $i-\mathrm{PrOH}$ & 70 & 2.0 & 3 \\
\hline 6 & 3.0 & $\mathrm{H}_{2} \mathrm{O}$ & 70 & 2.0 & 1 \\
\hline 7 & 3.0 & $\mathrm{MeCN}$ & 70 & 2.0 & 5 \\
\hline 8 & 3.0 & $\mathrm{PhMe}$ & 70 & 2.0 & 2 \\
\hline 9 & 3.0 & 1,4-dioxane & 70 & 2.0 & 3 \\
\hline 10 & 3.0 & THF & 70 & 2.0 & 2 \\
\hline 11 & 3.0 & $\mathrm{PC}^{b}$ & 70 & 2.0 & 8 \\
\hline 12 & 3.0 & $\mathrm{DME}$ & 70 & 2.0 & 13 \\
\hline 13 & 3.0 & DMSO & 70 & 2.0 & 16 \\
\hline 14 & 3.0 & DMSO & 70 & 4.0 & 21 \\
\hline 15 & 3.0 & DMSO & 80 & 4.0 & 43 \\
\hline 16 & 3.0 & - & 80 & 5.2 & 29 \\
\hline 17 & 3.0 & DMSO & 90 & 2.0 & 55 \\
\hline 18 & 3.0 & DMSO & 90 & 3.0 & 76 \\
\hline 19 & 3.0 & DMSO & 90 & 4.0 & 84 \\
\hline 20 & 3.0 & - & 90 & 5.2 & 67 \\
\hline 21 & 3.0 & DMSO & 100 & 4.0 & $98(94)^{c}$ \\
\hline
\end{tabular}

${ }^{a}$ Yield determined by ${ }^{1} \mathrm{H}$ NMR using 1,3,5-trimethoxybenzene as standard. ${ }^{b} \mathrm{PC}$ : propylene carbonate. ${ }^{\mathcal{C}}$ Isolated yield in parentheses.
In this procedure, the resulting insoluble precipitate $\mathbf{2} \mathbf{a}$ is simply washed with diethyl ether at the end of the reaction to remove the DMSO additive, excess dichloromethane and any trace of unreacted imidazole, directly affording the pure product as a white solid without the need for further purification. With these conditions in hand, a number of imidazole derivatives were evaluated in the reaction, leading to considerable steric, electronic and functional variability in the bis(imidazolium) dichloride salts obtained (Scheme 2). The presence of longer alkyl chains at the 1-position of the imidazole substrate had little to no effect on the reaction outcome, affording excellent yields in all cases (2a-2d). Notably, this is in contrast with some other methods such as Harwood's high pressure protocol (see Scheme 1b), ${ }^{8}$ where a significant decrease in yield was observed with $N$-alkyl substituents longer than methyl. $N$-prenylimidazole was also found to be compatible in the reaction (see $2 \mathbf{e}$ ), affording an alkene as functional handle for potential future derivatizations. As previously observed in other systems, ${ }^{\text {,h }}$ less nucleophilic $N$-phenylimidazole proved to be more challenging in this transformation (see $\mathbf{2 f}$ ), while $N$-mesitylimidazole $1 \mathbf{g}$ could afford a good yield of the corresponding bis(imidazolium) dichloride $\mathbf{2} \mathbf{g}$ when the reaction was run at $110^{\circ} \mathrm{C}$ for 48 hours. This significant variability in the efficiency of $N$-arylimidazoles to perform as effective nucleophiles is potentially due to the steric effect exerted by the ortho-methyl substituents, leading to deconjugation of both aromatic rings and thus a more nucleophilic imidazole ring in $\mathbf{1 g}$. Dibrominated bis(azolium) salt $\mathbf{2 h}$ could also be obtained using this protocol, albeit in lower yield due to significant decomposition observed in the reaction conditions, requiring recrystallization in methanol to obtain the pure product. ${ }^{13}$ The use of longer dichloroalkanes such as 1,2-dichloroethane (see $\mathbf{2 i}$ ) and 1,3-dichloropropane (see $\mathbf{2} \mathbf{j}$ ) afforded very good yields of the corresponding bis(imidazolium) dichloride salts when the electrophiles were used in stoichiometric amount. Notably, using an excess (3 equiv) of dichloroalkane in those two cases afforded a significant amount of undesired $\mathrm{N}$-chloroalkyl imidazolium intermediate, highlighting the distinct kinetic profile of those reactions as compared with the use of dichloromethane as electrophile.

\section{Scheme 2. Scope of Accessible Bis(imidazolium) Dichloride Salts ${ }^{a}$}

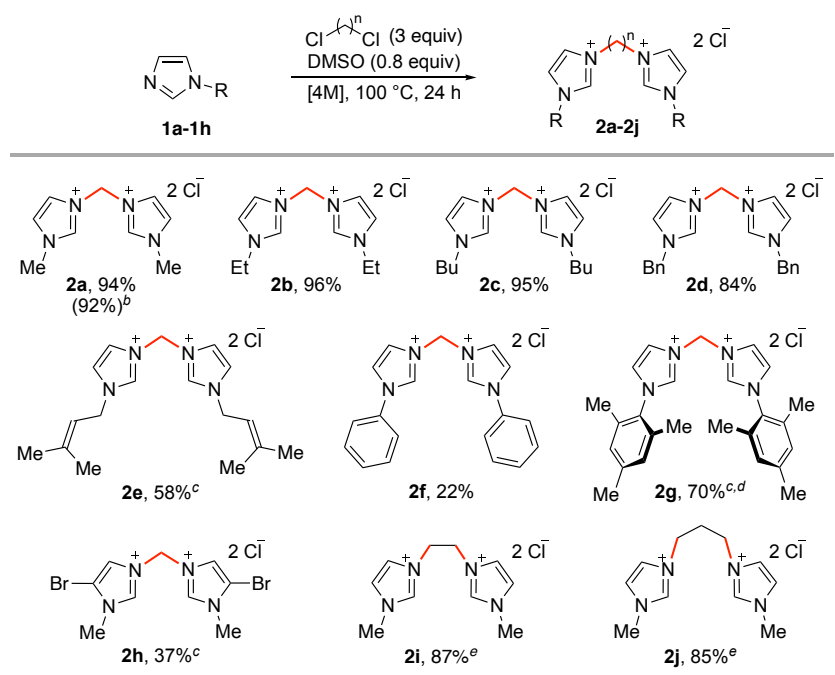

${ }^{a}$ All yields correspond to yields of isolated product on a $4.0 \mathrm{mmol}$ scale of imidazoles 1a-1h. ${ }^{b}$ Isolated yield on a $20 \mathrm{mmol}$ (1.64 g) scale of

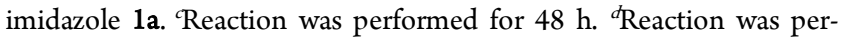
formed at $110^{\circ} \mathrm{C} .{ }^{e} 0.5$ equiv dichloroalkane was used. 
Our optimized conditions could also be extended to pyridine derivatives as substrates with high efficiency, affording the corresponding bis(pyridinium) dichloride salts $\mathbf{2 k - 2 l}$ in good to excellent yields (Scheme 3). This practical method should find significant utility, considering the widespread use of these compounds either as organic dications and reaction additives, ${ }^{14}$ linkers in materials chemistry, ${ }^{15}$ organic oxidants, ${ }^{16}$ or as aldehyde equivalents. ${ }^{17}$

\section{Scheme 3. Extension of the Method to Bis(pyridinium) Salts ${ }^{a}$}

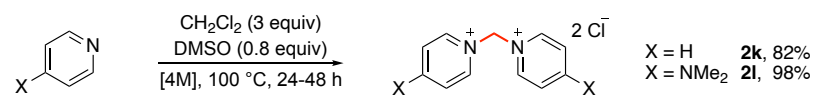

${ }^{a}$ All yields correspond to yields of isolated product on a $4.0 \mathrm{mmol}$ scale of pyridine or DMAP.

Due the simplicity of the method developed, we sought to evaluate its compatibility with the direct formation of metal-bis(carbene) complexes using modified literature conditions (Scheme 4). ${ }^{3 a, h, 18}$

Scheme 4. Direct Assembly of Bis(NHC) Metal Complexes from Imidazole la and Dichloromethane ${ }^{a}$

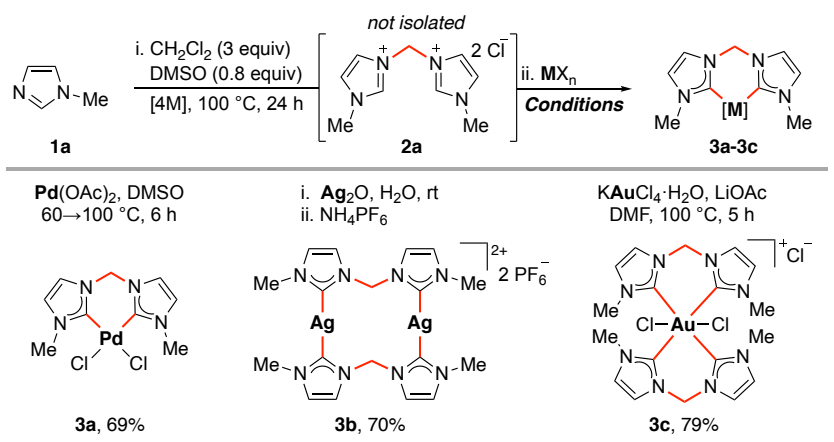

${ }^{a}$ All yields correspond to yields of isolated product from imidazole $1 \mathrm{a}$ (2-4 mmol scale).

For example, following our reaction, a solution of $\mathrm{Pd}(\mathrm{OAc})_{2}$ in DMSO was added to the resulting mixture and heated for 6 hours, affording $\mathrm{Pd}$ (II) complex $\mathbf{3 a}$ in good overall yield in a single pot from imidazole 1a. ${ }^{3 a}$ Notably, this complex is known to be an effective catalyst for various cross-coupling reactions $\mathrm{s}^{3 \mathrm{a}-\mathrm{c}}$ and $\mathrm{C}-\mathrm{H}$ activation processes. ${ }^{3-\mathrm{k}}$ Alternatively, the sequential addition of water, $\mathrm{Ag}_{2} \mathrm{O}$ and $\mathrm{NH}_{4} \mathrm{PF}_{6}$ to the crude mixture led to the one-pot formation of dinuclear $\mathrm{Ag}(\mathrm{I})$ complex $\mathbf{3 b}$ in $70 \%$ overall yield, ${ }^{18 a}$ which constitutes a versatile intermediate towards various $\mathrm{Cu}(\mathrm{I})$-, $\mathrm{Rh}(\mathrm{III})-, \mathrm{Au}(\mathrm{III})$ - or $\mathrm{Ir}(\mathrm{III})$-bis(NHC) complexes via simple transmetallation., ${ }^{4,5 a, 18 a, 19}$

(1) For seminal reports of the use of chelating bis(carbene) ligands in transition metal catalysis, see: (a) Herrmann, W. A.; Elison, M.; Fischer, J.; Köcher, C.; Artus, G. R. J. Metal Complexes of N-Heterocyclic CarbenesA New Structural Principle for Catalysts in Homogeneous Catalysis. Angew. Chem. Int. Ed. EngI. 1995, 34, 2371-2374. (b) Herrmann, W. A.; Reisinger, C.-P.; Spiegler, M. Chelating N-heterocyclic carbene ligands in palladiumcatalyzed heck-type reactions. J. Organomet. Chem. 1998, 557, 93-96.

(2) For reviews on the synthesis and applications of metal-poly (N-heterocyclic carbene) complexes, see: (a) Poyatos, M.; Mata, J. A.; Peris, E. Complexes with Poly(N-heterocyclic carbene) Ligands: Structural Features and Catalytic Applications. Chem. Rev. 2009, 109, 3677-3707. (b) Mata, J. A.; Poyatos, M.; Peris, E. Structural and catalytic properties of chelating bis- and tris-N-heterocyclic carbenes. Coord. Chem. Rev. 2007, 251, 841-859. (c) Normand, A. T.; Cavell, K. J. Donor-Functionalised N-Heterocyclic Carbene Complexes of Group 9 and 10 Metals in Catalysis: Trends and Directions. Eur. J. Inorg. Chem. 2008, 2781-2800.
Finally, Au(III)-NHC complex 3c, previously studied for its halidesensing properties, ${ }^{5 a}$ could be accessed in high overall yield via the addition of $\mathrm{KAuCl}_{4}$ and $\mathrm{LiOAc}$ to the crude product $2 \mathrm{a}^{1{ }^{18 \mathrm{~b}}}$ It is noteworthy that the overall yields observed herein for complexes $3 a-3 c$ are comparable ( $<3 \%$ difference) with the reported yields starting from preformed $2 \mathrm{a},{ }^{3 \mathrm{a}, \mathrm{h}, 18 \mathrm{a}-\mathrm{b}}$ highlighting the general compatibility of our method with a variety of known metalation procedures.

In summary, we report a general and expedient method for the synthesis of bis(imidazolium) dichloride salts via the use of DMSO as a key polar additive, and the process could be extended to the formation of versatile bis(pyridinium) dichloride salts difficult to access otherwise. Moreover, the conditions developed are shown to be compatible with subsequent metal-carbene formation, leading to the direct synthesis of various metal-bis(NHC) complexes from imidazoles. Considering the widespread utility of these salts in a variety of research fields, ${ }^{1-7}$ this practical approach should find considerable utility for the rapid and efficient access to such derivatives.

\section{ASSOCIATED CONTENT}

\section{Supporting Information}

Experimental details and spectroscopic data.

\section{AUTHOR INFORMATION}

\section{Corresponding Author \\ *Email: vlindsa@ncsu.edu}

\section{ORCID}

Kyle R. Penn: 0000-0002-7131-2752

Vincent N. G. Lindsay: 0000-0002-7126-325X

Notes

The authors declare no competing financial interest.

\section{ACKNOWLEDGMENT}

This work was supported by North Carolina State University startup funds. All nuclear magnetic resonance (NMR) spectroscopy and highresolution mass spectrometry (HRMS) measurements were performed by the Molecular Education, Technology, and Research Innovation Center (METRIC) at NC State University, which is supported by the State of North Carolina.

\section{REFERENCES}

(3) (a) Ahrens, S.; Zeller, A.; Taige, M.; Strassner, T. Extension of the Alkane Bridge in BisNHC-Palladium-Chloride Complexes. Synthesis, Structure, and Catalytic Activity. Organometallics 2006, 25, 5409-5415. (b) Taige, M. A.; Zeller, A.; Ahrens, S.; Goutal, S.; Herdtweck, E.; Strassner, T. New Pd-NHC-complexes for the Mizoroki-Heck reaction. J. Organomet Chem. 2007, 692, 1519-1529. (c) Valente, C.; Çalimsiz, S.; Hoi, K. H.; Mallik, D.; Sayah, M.; Organ, M. G. The Development of Bulky Palladium NHC Complexes for the Most-Challenging Cross-Coupling Reactions. Angew. Chem. Int. Ed. 2012, 51, 3314-3332. (d) Cao, C.; Zhuang, Y.; Zhao, J.; Peng, Y.; Li, X.; Shi, Z.; Pang, G.; Shi, Y. Binuclear palladium complexes bridged by dicarbene with different lengths and their application in Mizoroki-Heck reaction. Inorg. Chim. Acta 2010, 363, 3914-3918. (e) Aznarez, F.; Iglesias, M.; Hepp, A.; Veit, B.; Sanz Miguel, P. J.; Oro, L. A.; Jin, G.-X.; Hahn, F. E. Iridium(III) Complexes Bearing Chelating Bis-NHC Ligands and Their Application in the Catalytic Reduction of Imines. Eur. J. Inorg. 
Chem. 2016, 4598-4603. (f) Li, W.; Huang, M.; Liu, J.; Huang, Y.-L.; Lan, X.-B.; Ye, Z.; Zhao, C.; Liu, Y.; Ke, Z. Enhanced Hydride Donation Achieved Molybdenum Catalyzed Direct $N$-Alkylation of Anilines or Nitroarenes with Alcohols: From Computational Design to Experiment. ACS Catal. 2021, 11 10377-10382. (g) Liu, J.; Li, W.; Li, Y.; Liu, Y.; Ke, Z. Selective C-alkylation between Alcohols Catalyzed by N-Heterocyclic Carbene Molybdenum. Chem. Asian J. 2021, DOI: 10.1002/asia.202100959. (h) Ahrens, S.; Strassner, T. Detour-free synthesis of platinum-bis-NHC chloride complexes, their structure and catalytic activity in the $\mathrm{CH}$ activation of methane. Inorg. Chim. Acta 2006, 359, 4789-4796. (i) Meyer, D.; Strassner, T. CHactivation of methane - Synthesis of an intermediate? J. Organomet. Chem. 2015, 784, 84-87. (j) Munz, D.; Strassner, T. Propane Activation by Palladium Complexes with Chelating Bis(NHC) Ligands and Aerobic Cooxidation. Angew. Chem. Int. Ed. 2014, 53, 2485-2488. (k) Ma, D.; Zhang, C.; Chen, Z.-N.; Xu, X. Rational design of model Pd(II)-catalysts for C-H activation involving ligands with charge-shift bonding characteristics. Phys. Chem. Chem. Phys. 2017, 19, 2417-2424. (1) Algarra, A. G.; Galindo, J. C. G.; Puerta, M. C.; Valerga, P.; Jiménez-Tenorio, M. Activation of Dichloromethane by a Bis-NHC $\mathrm{Cp}^{*} \mathrm{Ru}$ Complex: Formation of a Pentamethyl(chloromethyl)cyclopentadiene Ligand. Organometallics 2021, 40, 2405-2408. (m) Subramanium, S. S.; Handa, S.; Miranda, A. J.; Slaughter, L. M. Simple Silver Salts and Palladium Bis(N-heterocyclic carbene) Complexes As Complementary Catalysts for the Nazarov Cyclization. ACS Catal. 2011, 1, 1371-1374. (n) Volpe, A.; Sartorel, A.; Graiff, C.; Bonchio, M.; Biffis, A.; Baron, M.; Tubaro, C. Chelating di(N-heterocyclic carbene) complexes of iridium(III): Structural analysis, electrochemical characterisation and catalytic oxidation of water. J. Organomet. Chem. 2020, 917, 121260. (o) Thoi, V. S.; Chang, C. J. Nickel N-heterocyclic carbene-pyridine complexes that exhibit selectivity for electrocatalytic reduction of carbon dioxide over water. Chem. Commun. 2011, 47, 6578-6580.

(4) Wang, C.; Liu, J.; Tian, Z.; Tian, M.; Tian, L.; Zhao, W.; Liu, Z. Halfsandwich iridium N-heterocyclic carbene anticancer complexes. Dalton Trans. 2017, 46, 6870-6883.

(5) (a) Baron, M.; Dall'Anese, A.; Miolato, A.; Cairoli, M. L. C.; Di Marco, V.; Graiff, C.; Pöthig, A.; Tubaro, C. New homoleptic gold carbene complexes via $\mathrm{Ag}-\mathrm{Au}$ transmetalation: synthesis and application of $\left[\mathrm{Au}(\mathrm{diNHC})_{2}\right]^{3+}$ cations as ${ }^{1} \mathrm{H}-\mathrm{NMR}$ and UV-vis halide sensors. New J. Chem. 2020, 44, 5343-5353. For halide-sensing properties of analogous calix [n] imidazolium species, see also: (b) Chun, Y.; Jiten Singh, N.; Hwang, I.C.; Woo Lee, J.; Yu, S. U.; Kim, K. S. Calix $[n]$ imidazolium as a new class of positively charged homo-calix compounds. Nat. Commun. 2013, 4, 1797.

(6) (a) Hao, P.; Zhang, M.; Zhang, W.; Tang, Z.; Luo, N.; Tan, R.; Yin, D. Polyoxometalate-based Gemini ionic catalysts for selective oxidation of benzyl alcohol with hydrogen peroxide in water. Catal. Sci. Technol. 2018, 8, 4463-4473. (b) Sayyahi, S. Preparation and Application of 1,1'-Bis-methyl-3,3'-methylene-bisimidazolium Dicyanide as a Task-Specific Ionic liquid: An Efficient Catalyst in Benzoin Condensations. Chem. Sci. Trans. 2012, 1, 9-12. (c) Sayyahi, S.; Rezaee, H. M.; Khalfabadi, F. S.; Gorjizadeh, M. 1,1'-Bis-Methyl-3, 3-Methylenebisimidazolium Dichloride as an Efficient Phase Transfer Catalyst for Ring Opening of Epoxides Using $\mathrm{SCN}^{-}$and $\mathrm{N}_{3}$ in water. J. Chem. Res. 2012, 36, 396-397.

(7) García-Fernández, A.; Marcos-Cives, I.; Platas-Iglesias, C.; CastroGarcía, S.; Vázquez-García, D.; Fernández, A.; Sánchez-Andújar, M. Diimidazolium Halobismuthates $[\mathrm{Dim}]_{2}\left[\mathrm{Bi}_{2} \mathrm{X}_{10}\right]\left(\mathrm{X}=\mathrm{Cl}^{-}, \mathrm{Br}^{-}\right.$, or I- $)$: A New Class of Thermochromic and Photoluminescent Materials. Inorg. Chem. 2018, 57, 7655-7664.

(8) Harwood, L. M.; Pitt, P.; Scott, J. L.; Sousa, D. Ultra-high pressure direct syntheses of bis(imidazolium-3-yl)alkane dichlorides. Tetrahedron 2019, 75, 130639.

(9) For a solvent-free synthesis of alkane-bridged bis(imidazolium) dichloride salts leading to only $33 \%$ yield of $\mathbf{2 a}$ with dichloromethane, see: Cao, C.; Zhuang, Y.; Zhao, J.; Liu, H.; Geng, P.; Pang, G.; Shi, Y. Green Synthesis of Alkane Bridged Bisimidazolium Salts Under Solvent-Free Conditions. Synth. Commun. 2012, 42, 380-387.

(10) (a) Rudine, A. B.; Walter, M. G.; Wamser, C. C. Reaction of Dichloromethane with Pyridine Derivatives under Ambient Conditions. $J$. Org. Chem. 2010, 75, 4292-4295. For related studies, see: (b) Almarzoqi, B.; George, A. V.; Isaacs, N. S. The Quarternisation of Tertiary Amines with
Dihalomethane. Tetrahedron 1986, 42, 601-607. (c) Anders, E.; Opitz, A. Wermann, K.; Wiedel, B.; Walther, M.; Imhof, W.; Görls, H. Preparation and Conversion of $N$-Halomethylpyridinium Halides. Comparison with Related Compounds. J. Org. Chem. 1999, 64, 3113-3121.

(11) For analogous reactions of aliphatic amines with dichloromethane, see: (a) Hansen, S. H.; Nordholm, L. N-alkylation of tertiary aliphatic amines by chloroform, dichloromethane and 1,2-dichloroethane. J. Chromatogr. A 1981, 204, 97-101. (b) Beckett, A. H.; Ali, H. M. Artifacts produced by using dichloromethane in the extraction and storage of some antihistaminic drugs. J. Chromatogr. A 1979, 177, 255-262. (c) Wright, D.; Wulff, C. Chloromethyltriethylammonium Chloride. A Serendipitous Preparation. J. Org. Chem. 1970, 35, 4252-4252.

(12) (a) Baidya, M.; Brotzel, F.; Mayr, H. Nucleophilicities and Lewis basicities of imidazoles, benzimidazoles, and benzotriazoles. Org. Biomol. Chem. 2010, 8, 1929-1935. (b) Byrne, P. A.; Kobayashi, S.; Breugst, M.; Laub, H.; Mayr, H. Quantification of the nucleophilic reactivity of nicotine. J. Phys. Org. Chem. 2016, 29, 759-767. (c) Nigst, T. A.; Ammer, J.; Mayr, H. Photogeneration of Benzhydryl Cations by Near-UV Laser Flash Photolysis of Pyridinium Salts. J. Phys. Chem. A. 2012, 116, 8494-8499. (d) Brotzel, F.; Kempf, B.; Singer, T.; Zipse, H.; Mayr, H. Nucleophilicities and Carbon Basicities of Pyridines. Chem. Eur. J. 2007, 13, 336-345.

(13) See the Supporting Information document for details.

(14) (a) Lu, Y.-B.; Wang, C.-H.; Du, H.-J.; Niu, Y.-Y. Two novel cationinduced supramolecular polymers with 2-3D polymeric cuprous thiocyanate frameworks: Synthesis, characterization and photocatalytic activities for the degradation of organic dye contaminants. Inorg. Chim. Acta 2016, 450, 154-161. (b) Lebel, H.; Piras, H. Stereoselective Synthesis of Chiral Sulfilimines from $N$-Mesyloxycarbamates: Metal-Nitrenes versus MetalNitrenoids Species. J. Org. Chem. 2015, 80, 3572-3585. (c) Azek, E.; Lai, C.; Ernzerhof, M.; Lebel, H. Rhodium-Catalyzed Sulfimidation Reactions: A Computational Study. Organometallics 2021, DOI: 10.1021/acs.organomet.1c00367. (d) Long, Z.; Zhou, Y.; Ge, W.; Chen, G.; Xie, J.; Wang, Q.; Wang, J. Ionic-Liquid-Functionalized Polyoxometalates for Heterogeneously Catalyzing the Aerobic Oxidation of Benzene to Phenol: Raising Efficacy through Specific Design. ChemPlusChem 2014, 79, 1590-1596. (e) Yan, W.-H.; Ji, E-Y.; Shen M.-L.; Li, Z.-Y.; Li, X.; Xu X.-L. Two Ion-pair Complexes Constructed by $\left[\mathrm{M}(\mathrm{mnt})_{2}\right]^{\mathrm{n}-}(\mathrm{M}=\mathrm{Ni}, \mathrm{Co}$, mnt $=$ Maleonitriledithiolate): Syntheses, Characterization and Thermal Stability. Chinese J. Struct. Chem. 2015, 34, 306-312. (f) Al-Ktaifani, M.; Rukiah, M. $N, N$ 'methylenedipyridinium $\mathrm{Pt}(\mathrm{II})$ and $\mathrm{Pt}(\mathrm{IV})$ hybrid salts: synthesis, crystal and molecular structures of $\left[\left(\mathrm{C}_{5} \mathrm{H}_{5} \mathrm{~N}\right)_{2} \mathrm{CH}_{2}\right] \cdot\left[\mathrm{PtCl}_{4}\right]$ and $\left[\left(\mathrm{C}_{5} \mathrm{H}_{5} \mathrm{~N}\right)_{2} \mathrm{CH}_{2}\right] \cdot\left[\mathrm{PtCl}_{6}\right]$. Chemical Papers 2012, 66, 1032-1038. (g) Brenčič, J. V.; Modec, B. The mononuclear tungsten(V) complexes: The preparation and the X-ray structures of a series of $\left[\operatorname{WOX}_{4}\left(\mathrm{H}_{2} \mathrm{O}\right)\right]^{-}(\mathrm{X}=\mathrm{Cl}$, Br) salts. Inorg. Chem. Commun. 2011, 14, 1369-1372. (h) Al-Ktaifani, M.; Rukiah, M. Synthesis and crystal and molecular structures of $N, N^{\prime}$-methylenedipyridinium tetrachlorozincate(II) and $N, N$-methylenedipyridinium tetrachlorocadmate(II). Chemical Papers 2011, 65, 469-476. (i) Niu, Y.-Y.; Wu, B.-L.; Guo, X.-L.; Song, Y.-L.; Liu, X.-C.; Zhang, H.-Y.; Hou, H.-W.; Niu, C.-Y.; Ng, S.-W. A Systematic Design and Facile Construct of Metal Pseudohalide Frameworks Directed By 1, $\omega$-Bis (pyridinium)alkane Cations. Cryst. Growth Des. 2008, 8, 2393-2401. (j) Peymann, T.; Knobler, C. B.; Khan, S. I.; Hawthorne, M. F. Dodecamethyl-closo-dodecaborate(2-). Inorg. Chem. 2001, 40, 1291-1294. (k) Zander, S.; Preetz, W. Darstellung, ${ }^{11} \mathrm{~B}-$ ,${ }^{13} \mathrm{C}$-NMR- und Schwingungsspektren von $\mathrm{Cs}_{2}\left[\mathrm{~B}_{6} \mathrm{H}_{5}\left(p-\mathrm{C}_{6} \mathrm{H}_{4}\left(\mathrm{NO}_{2}\right)\right)\right]$ und $\mathrm{Cs}_{2}\left[\mathrm{~B}_{6} \mathrm{H}_{5}\left(\mathrm{C}_{6} \mathrm{H}_{3}-1-\left(\mathrm{CH}_{3}\right)-5-\left(\mathrm{NO}_{2}\right)\right)\right]$ sowie Kristallstruktur von $\left(\mathrm{CH}_{2} \mathrm{Py}_{2}\right)\left[\mathrm{B}_{6} \mathrm{Cl}_{5}\left(p-\mathrm{C}_{6} \mathrm{H}_{4}\left(\mathrm{NO}_{2}\right)\right)\right] \cdot \mathrm{CH}_{3} \mathrm{CN} /$ Preparation, ${ }^{11} \mathrm{~B},{ }^{13} \mathrm{C}-\mathrm{NMR}$ and Vibrational Spectra of $\mathrm{Cs}_{2}\left[\mathrm{~B}_{6} \mathrm{H}_{5}\left(p-\mathrm{C}_{6} \mathrm{H}_{4}\left(\mathrm{NO}_{2}\right)\right)\right], \mathrm{Cs}_{2}\left[\mathrm{~B}_{6} \mathrm{H}_{5}\left(\mathrm{C}_{6} \mathrm{H}_{3}-1-\right.\right.$ $\left.\left.\left(\mathrm{CH}_{3}\right)-5-\left(\mathrm{NO}_{2}\right)\right)\right]$ and Crystal Structure of $\left(\mathrm{CH}_{2} \mathrm{Py}_{2}\right)\left[\mathrm{B}_{6} \mathrm{Cl}_{5}(p-\right.$ $\left.\left.\mathrm{C}_{6} \mathrm{H}_{4}\left(\mathrm{NO}_{2}\right)\right)\right] \cdot \mathrm{CH}_{3} \mathrm{CN}$. Z. Naturforsch. B2000, 55, 1031-1036.

(15) (a) Marcos, I.; Domarco, O.; Peinador, C.; Fenández, A.; Fernández, J. J.; Vázquez-García, D.; García, M. D. Self-assembly of dinuclear $\mathrm{Pd}(\mathrm{II}) / \mathrm{Pt}(\mathrm{II})$ metallacyclic receptors incorporating $\mathrm{N}$-heterocyclic carbene complexes as corners. Dalton Trans. 2017, 46, 4182-4190. (b) Frasconi, M.; Kikuchi, T.; Cao, D.; Wu, Y.; Liu, W.-G.; Dyar, S. M.; Barin, G.; Sarjeant, A. 
A.; Stern, C. L.; Carmieli, R.; Wang, C.; Wasielewski, M. R.; Goddard, W. A.; Stoddart, J. F. Mechanical Bonds and Topological Effects in Radical Dimer Stabilization. J. Am. Chem. Soc. 2014, 136, 11011-11026. (c) Blanco, V.; García, M. D.; Platas-Iglesias, C.; Peinador, C.; Quintela, J. M. Dynamic formation of self-organized corner-connected square metallocycles by stoichiometric control. Chem. Commun. 2010, 46, 6672-6674. (d) Forgan, R. S.; Friedman, D. C.; Stern, C. L.; Bruns, C. J.; Stoddart, J. F. Directed self-assembly of a ring-in-ring complex. Chem. Commun. 2010, 46, 5861-5863. (e) Blanco, V.; Gutiérrez, A.; Platas-Iglesias, C.; Peinador, C.; Quintela, J. M. Expanding the Cavity Size: Preparation of 2:1 Inclusion Complexes Based on Dinuclear Square Metallocycles. J. Org. Chem. 2009, 74, 6577-6583. (f) Peinador, C.; Blanco, V.; Quintela, J. M. A New Doubly Interlocked [2]Catenane. J. Am. Chem. Soc. 2009, 131, 920-921. (g) Blanco, V.; Chas, M.; Abella, D.; Pía, E.; Platas-Iglesias, C.; Peinador, C.; Quintela, J. M. Self-Assembly of 1:2 Inclusion Complexes between a Metallocycle Host and Dihydroxyaromatic Guests: A Redox Controlled Complexation Process. Org. Lett. 2008, 10, 409-412. (h) Blanco, V.; Chas, M.; Abella, D.; Peinador, C.; Quintela, J. M. Molecular Catenation via Metal-Directed Self-Assembly and $\pi$-Donor/ $\pi$-Acceptor Interactions: Efficient One-Pot Synthesis, Characterization, and Crystal Structures of [3]Catenanes Based on Pd or Pt Dinuclear Metallocycles. J. Am. Chem. Soc. 2007, 129, 13978-13986.

(16) (a) Tcyrulnikov, N. A.; Varadharajan, R.; Tikhomirova, A. A.; Pattabiraman, M.; Ramamurthy, V.; Wilson, R. M. Modulation of Reduction Potentials of Bis(pyridinium)alkane Dications through Encapsulation within Cucurbit[7]uril. J. Org. Chem. 2019, 84, 8759-8765.

(17) (a) Augustine, J. K.; Naik, Y. A.; Mandal, A. B.; Chowdappa, N.; Praveen, V. B. gem-Dibromomethylarenes: A Convenient Substitute for Noncommercial Aldehydes in the Knoevenagel-Doebner Reaction for the Synthesis of $\alpha, \beta$-Unsaturated Carboxylic Acids. J. Org. Chem. 2007, 72, 9854-9856. (b) Anders, E.; Wermann, K.; Wiedel, B.; Günther, W.; Görls, H. Syntheses of a Novel Class of 5/6/5-Heterocycles: Convenient Routes from Aldehydes to Bis(1,3,4-thiadiazolo)-1,3,5-triazinium Halides. Eur. J. Org. Chem. 1998, 2923-2930. (c) Olofson, R. A.; Zimmerman, D. M. Chemistry of bisminium cations. I. Synthesis of 1-deuterioaldehydes. J. Am. Chem. Soc. 1967, 89, 5057-5059.

(18) (a) Quezada, C. A.; Garrison, J. C.; Panzner, M. J.; Tessier, C. A.; Youngs, W. J. The Potential Use of Rhodium N-Heterocyclic Carbene Complexes as Radiopharmaceuticals: The Transfer of a Carbene from $\mathrm{Ag}(\mathrm{I})$ to $\mathrm{RhCl}_{3} \cdot 3 \mathrm{H}_{2} \mathrm{O}$. Organometallics 2004, 23, 4846-4848. (b) Mageed, A. H.; Skelton, B. W.; Baker, M. V. Stable Au ${ }^{\text {III }}$ complexes with four N-heterocyclic carbene groups can be prepared in high yield directly from $\mathrm{KAuCl}_{4}$. Dalton Trans. 2017, 46, 7844-7856. For selected examples of the synthesis of related metal-bis(NHC) complexes, see: (c) Altmann, P. J.; Weiss, D. T.; Jandl, C.; Kühn, F. E. Exploring Coordination Modes: Late Transition Metal Complexes with a Methylene-bridged Macrocyclic Tetra-NHC Ligand. Chem. Asian J. 2016, 11, 1597-1605. (d) Weiss, D. T.; Altmann, P. J.; Haslinger, S.; Jandl, C.; Pöthig, A.; Cokoja, M.; Kühn, F. E. Structural diversity of late transition metal complexes with flexible tetra-NHC ligands. Dalton Trans. 2015, 44, 18329-18339.

(19) (a) Matsumoto, K.; Matsumoto, N.; Ishii, A.; Tsukuda, T.; Hasegawa, M.; Tsubomura, T. Structural and spectroscopic properties of a copper(I)-bis(N-heterocyclic)carbene complex. Dalton Trans. 2009, 67956801. (b) Volpe, A.; Sartorel, A.; Tubaro, C.; Meneghini, L.; Di Valentin, M.; Graiff, C.; Bonchio, M. N-Heterocyclic Dicarbene Iridium(III) Catalysts Enabling Water Oxidation under Visible Light Irradiation. Eur. J. Inorg. Chem. 2014, 665-675. (c) Sabiah, S.; Lee, C.-S.; Hwang, W.-S.; Lin, I. J. B. Facile $\mathrm{C}-\mathrm{N}$ Bond Cleavage Promoted by Cuprous Oxide: Formation of C-C-Coupled Biimidazole from Its Methylene-Bridged Congener. Organometallics 2010, 29, 290-293. 


\section{TOC GRAPHIC}

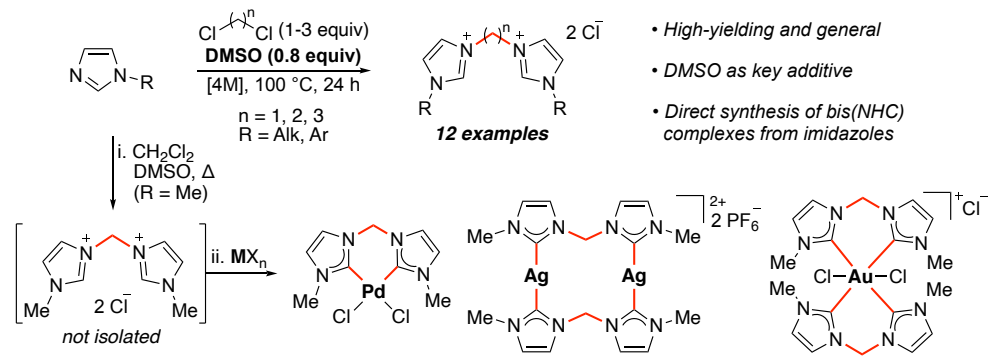

